\title{
Is Blended Learning Making Us Stupid, Too?
}

\author{
Ray Archee \\ School of Humanities and Communication Arts, University of Western Sydney, Sydney, Australia \\ Email: r.archee@uws.edu.au
}

Received 29 July 2015; accepted 14 September 2015; published 18 September 2015

\begin{abstract}
The title of this paper echoes Nicholas Carr's (2008) article, Is Google Making Us Stupid?, which evoked heated debate around the issue of whether the Internet was having negative effects upon human concentration and learning. While this paper agrees that blended learning has the same issues as the Internet, blended learning is under the control of organizations, institutions, instructors and students. Whether our brains are being changed for better or worse is not the critical question, but how much confidence we ascribe to blended learning. This paper argues that blended learning should be regarded as blended teaching because the phrase comprises a contested assumption. Educators, by their selection of traditional and online media, have complete control over this teaching, but students, in the end, are the ultimate arbiters of their own learning.
\end{abstract}

\section{Keywords}

\section{Blended Learning, Online Learning, E-Learning, Traditional Learning, Teaching}

\section{Introduction}

My own teaching experience with blended learning started in 1996 when I received a grant to purchase a Linuxbased server, which was placed on the backbone of my university's network. Since that time I have created web pages, bulletin boards, and chat sites and run courses, which have always included a website component, effectively creating blended learning, before the term became de rigueur, around the year, 2005. In the 1990's I ran elective classes in researching websites, forums and chat sites. In the next decade, the startup years of Learning Management Systems such as WebCT and Moodle, I continuously ran my own set of custom Web-based support pages, piloting Flash tutorials, and voice messaging, while most instructors used banal proprietary software or nothing at all. In 2000, I allowed students to attend in fully online mode thus creating my institution's first totally online subject. More recently I have been utilizing platform savvy, Wordpress sites, opening up new forms of interactivity such as online research and writing labs, and video presentation assignments.

The main hypothesis of the Nicholas Carr's article [1] was that Google (a symbol for the Internet) was having a negative impact on the way in which people focus and reflect, thus our learning and thinking were diminished by using the Internet. Carr's article created a stream of debate, some critics agreed, some denied this singular idea that the screen-based environment was destroying forever our ability to concentrate and learn the way we used to. Reference [2] agreed with Carr's finding that people displayed different reading behavior online in contrast to offline reading. They found that concentration, comprehension, absorption and recall rates were significantly lower when reading material online, as opposed to offline. This paper asks if blended learning contributes 
to cognitive change, and decidedly concludes, no.

\section{History of Blended Learning}

While there has always been institutional pressure for instructors to embrace new technologies, in order to evolve, or fail [3], the academic literature is somewhat united in a single question: What is the definition of "blended learning"? The term is not the brainchild of an educational theorist, but a hybrid concept, evolving from the similarly affected concepts of "e-learning" and "v-learning". Without an agreed upon definition, there can be no way to compare the variety of programs, units, and modules, which purport to employ blended learning [4], and with every passing year, new technologies are adding even more complexity to identifying the exact ingredients of this hybrid recipe.

The general consensus is the blended learning comprises a hybrid mix of traditional face-to-face (f2f) teaching, with a range of mediated communication technologies such as websites, lecture pods, sound files, interactive forums, and chat sites, and often comprising online assignment submission and assessment. The exact mix of traditional and online media has considerable variation around the world.

\subsection{Origins}

Arguably, blended learning had its origin in distance education courses, which sometimes combined f2f instruction with print-based course materials (mid 19th C) and the radio (1920s). These materials were posted out to students who often lived in rural areas of USA, UK, Europe and Australia. Media technologies of radio, television and even the telephone were used to supplement basic print. One variant of such courses was the requirement that students attend intensive periods of f2f instruction, from a few days to weeks, giving rise to the hybrid analogy with contemporary blended learning. Many college degrees were designed specifically for this kind of hybrid education. These colleges may have later been aggregated into university networks, but many countries still retain such institutions, which in turn have morphed into blended learning specialists. Even metropolitan universities sometimes had a distance education branch, which competed for remote students in hybridized ways. Many postgraduate diplomas and certificates belong to this genre of course, which appealed to working students who could flexibly combine full-time work and education or training.

The widespread rollout of the Internet in the mid 1990's, plus falling prices for personal computers and network access has led to almost universal access to the Web, freeing instructors to design courses with unsurpassed available resources, along with new methods of delivery, assessment and interactivity for students and instructors alike. Developments in technology such as much faster CPUs, better monitors, bigger hard drives, and broadband network access has facilitated not only the popularity of the Internet, but also the establishment of a range of online learning degrees-some fully online, but many still retaining a f2f component. Many existing distance education courses were rapidly transformed into Web-based courses, some with a residential component, automatically creating variants of what we now call blended learning.

Perhaps the most significant development at the institutional level has been the widespread implementation of Learning Management Systems, such as Edmodo, Blackboard and the freely available, Moodle. These organization-wide systems have simplified the creation of websites. These same systems have also been self-serving, because once fully implemented, institutions are locked into a particular online infrastructure, user interface and related staff training. The main benefit was that instructors did not need specialist knowledge in HTML coding, hyperlinking and file uploading; any instructor could offer a wide variety Web resources to every student in a course at any time of the day and in any location across the globe. But Learning Management Systems have not guaranteed student learning, merely their access [5].

\subsection{E-Learning and Blended Learning}

A multiplicity of terms: online learning, e-learning, Web-based learning and derived concepts such as m-learning, and v-learning have all come into existence because of the perceived success of Learning Management Systems from about 2000 onwards. While the reality of this success for students is dubious at best, e-learning has been suggested as the eventual model for the future of all successful tertiary institutions [6]. In its most extreme form, e-learning removes the need for f2f instructors, the major expenditure for any institution, replacing people with a vast array of content from a variety of media sources. If students do not need to attend f2f, then 
buildings, libraries and services can also be removed from the equation, leaving definite profits for institutions in this era of accelerated financial competition and diminishing government expenditure on tertiary education [7].

Enter blended learning, now an accepted buzz phrase surrounding both school education, and higher education levels [8] [9]. Instructors have long realized the end result of e-learning is unemployment, and so have sought to use their expertise as instructional designers and thus incorporate e-learning into their day to day classroom teaching practices. Politically, this satisfies bureaucrats wishing to keep up with technology, and it grants teachers substantial control of their own programs of study, adding flexibility to student attendance and providing access to vast learning resources. If blended learning needs expertise and careful preparation, then instructors will still be needed as the master designers of these educational recipes of the future.

There have been hundreds of previous studies, which have analyzed blended learning outcomes used in specific courses or programs of study, but only a handful of meta-analyses that attempt summarize and synthesize the entire literature to date. The slightly earlier 2013 meta-study [10] compared online learning with f2f, and blended learning with f2f, and concluded there were only modest gains for online learning, but significant gains for blended learning, when compared with purely traditional forms of instruction. They highlight the confounding factors of additional time, resources and course elements, which encouraged more interaction between students in blended learning conditions. This additional interaction may be the main reason for the significant outcomes for blended learners, and not f2f/online media mix, per se.

The more recent 2014 meta-analysis [11] focused solely on higher education, and included studies from 1990 in their review. This meta-study found similar results in that blended learning benefits students on average one third of a standard deviation, with more specific gains enabled by the genre of computer support, and the kind of interaction that is encouraged. Reference [12] described four patterns or forms of blended learning: 1) a hybrid mix of web-based technologies; 2) a fusion of pedagogical practices; 3) an amalgamation of any form of instructional technology with f2f instructor-led situations, and 4) a combination of instructional technology with actual job tasks to create a mixture of learning and working. Reference [11] notes that while the majority of studies depict a range of disparate digital technologies, the f2f traditional classrooms are not as well described. This would seem to be a large oversight, in that the crucial element of the instructor is subsumed under an umbrella concept. Surely the instructor is of central concern in this unwieldly mix of old and new media?

\section{Leximancer Analysis of Literature}

A novel method of examining and evaluating academic literature is to employ the Leximancer software to analyze embedded themes and concepts. Leximancer is software from University of Queensland that objectively analyses any kind of text document and identifies key themes and concepts yielding key insights via graphical and interactive text displays. It does not simply count words, but evaluates relationships between concepts and themes. All two hundred and forty four, peer-reviewed, full-text articles from the ProQuest database, which contained "blended learning" (in the title of the article) were inputted into Leximancer. The articles, comprising over 2000 pages of plain text, yielded the following cluster diagram:

The heat map (Figure 1) is coded in terms of the hotness of the themes: learning is red and most important, followed by use and then online, students, research etc. Thus, the theme of learning is found to be the most significant theme over the 244 academic papers. What is astounding in this literature is that the concept of teaching (unseen) seems to be a minor concept, with a relevance of $20 \%$ compared with learning (100\%). Whatever the actual results of these studies, there is a fundamental conceptual flaw in the whole blended learning impetus, and that is by using a mix of online and f2f media, one automatically creates new learning. By continuous use of the phrase, "blended learning" educators are assuming that learning is genuinely occurring. Methodologically, many studies measure student satisfaction as opposed to actual grades. Surely, the buzz phrase should be renamed "blended teaching"?

\section{Online Learning Experiences}

There have been several studies from the Columbia College Research Center (see http://ccrc.tc.columbia.edu/Online-Education-Instructional-Technology.html), which have shown that online methods of instruction do not suit the weakest students, or students who come from a non-English speaking background. Studying hundreds of thousands of students in Washington and Virginia, most studies showed 


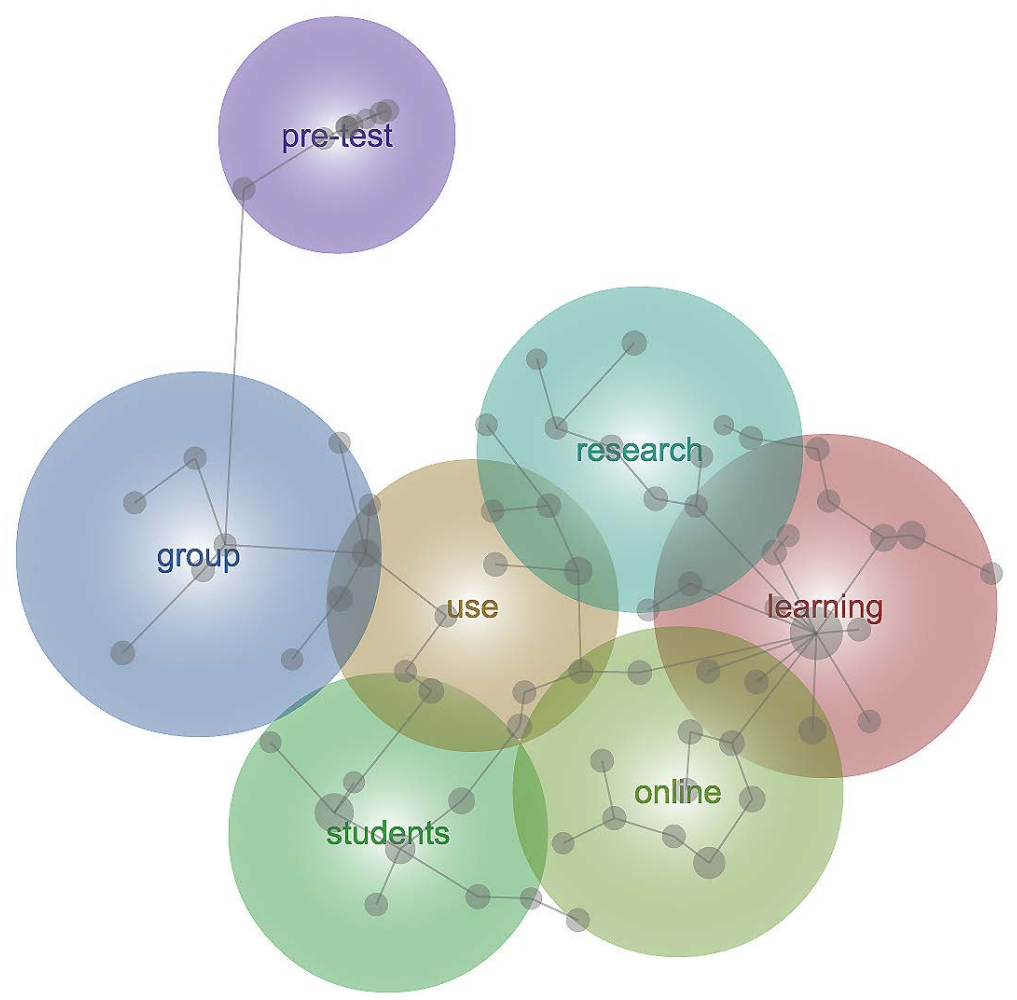

Figure 1. Leximancer theme map of "blended learning” search of 244 articles from ProQuest.

strong negative impacts of using e-learning with students studying at the technical and community level. One of the largest problems was that of self-confidence. Students need engagement with a teacher in order to feel comfortable and achieve success. In a totally online context, such students feel isolated and alone, and simply drop out [13] [14].

Another large-scale Canadian study [15] surveyed over 8000 students in higher education courses around that country and found that students gave slightly lower satisfaction scores to courses with more e-resources; and they gave substantially high ratings to more traditional courses as places where they "learned more". However, when asked if they wanted more online resources, most students said "yes". The study concludes that these so-called "digital natives" who have grown up with the Internet, do not prefer to be immersed in online locations, and prefer old-fashioned classroom settings. This is quite understandable and concurs with my own experiences. Students prefer to be guided in their learning by experts, and they enjoy observing and interacting with their peers in a f2f class. Online delivery is experienced as isolating, and online lectures judged to be too boring, with students realizing that the motivation to logon and study is a near-impossible task, given their busy personal lives and all the distractions that the Internet offers.

It should be noted that the Canadian study took for granted that students had equal experiences since they all had equitable access. My experience based upon anecdotes and Web analytics is that there is huge variation in the usage patterns of students (and thus experiences), some accessing websites only three or four times a semester, some visiting several times a week. For example, a useful resource should be the video recordings of 7 guest lectures given in a research methods unit of mine in 2015 (cohort was 225). The lecture rooms were barely half full for the live f2f lectures. Logs show that each recorded lecture was viewed a handful of times (two or three) by subsequent online accesses. I would estimate that only around $50 \%-55 \%$ of students attended in person and less than $2 \%$ viewed the lectures online. I have a custom Wordpress site for my teaching of the same research unit. Logs show 3205 accesses for the whole 13-week semester. This is an average of about 1.1 accesses per student per week, and the site was used in class for teaching every week, thus viewed by students in class! The same problem occurs with online course feedback surveys, which are avoided by the majority of students, producing return rates as low as $10 \%$ for some units. While all universities can record such Web analytics, 
very few publicize such disconcerting statistics.

\section{Online Assessment}

The use of online drop boxes, and online marking is becoming popular in Australian universities, amongst others. Blackboard has a numerous facilities for marking online students' assignments, and includes the popular Turnitin duplication checking software. Apart from instructor confusion at how to actually view, navigate and place comments on these documents, and similar student issues, several problems are created by online assessment. One problem is the release time/date for handing marks back. Instructors are rarely present for this event, some students do badly, and feedback may be inadequate or difficult for students to access on these systems. In fact most students usually are never informed or trained in the use of online feedback mechanisms, and thus suffer inconsistently depending on their ability to locate feedback training from friends or instructors. The net result is anxiety, injury to student self-confidence and mass complaints to staff. As unit coordinator, I usually receive a dozen emails asking how students lost 4 or 5 marks, or why they failed. This was usually not a feature of paper-based assignments in the past.

Another problem is that of privacy in terms of instructor comments on student papers-this has traditionally been a one-to-one relationship between tutors and students, but is now publicly available, insofar as staff with permission can access any students' papers replete with tutor comments. There are also many, many glitches in the software-slowness, hiccups, missing papers, and the system releasing grades before the appropriate date. Personally, I find marking hundreds of online assignments to be tedious, tiring and mind numbing; old-fashioned paper-based marking was much easier.

One very useful artifact of online assessment is that a coordinator can truly moderate marks, on an assignment-by-assignment basis, given all the marks and assignments can be downloaded and examined. Turnitin is also very useful for catching cheats and academic miscreants. But a combined system, which incorporates both online submission and paper-based marking, would be ideal, creating the best of both worlds. This real blended marking system, however, is not the approved one at most institutions.

\section{Final Thoughts}

The main reason that blended learning cannot possibly be adding to the cognitive transformation that Nicholas Carr so vigorously explored, and [2] have supported with reading evaluations, is that blended learning sites seem to be accessed so infrequently by the majority of students. While senior administrators wrestle with policy decisions, and instructors take delight in mastering iMovie and Photoshop, students themselves are unconvinced of the value of the new media, and simply tolerate the blended learning invasions into their social media lives. Do blended media excite them? Unlikely. Do they use educational websites on a regular basis? Yes, once a week, in class, when everyone else is doing the same thing. Do they use the website if they miss a class? Sometimes. Maybe.

This weekly class use of websites is akin to paper-based notes, which I used to photocopy and distribute to students each week. However, I have always preferred websites because I can prepare and organize content, exercises, resources and readings ahead of time, and re-use work in subsequent years. But, I do not delude myself believing that my students will be excited, thankful, or use my prepared resources more than once a week. I like blended learning, which I have used for the majority of my academic career. I call it teaching.

\section{References}

[1] Carr, N. (2008) Is Google Making Us Stupid? What the Internet Is Doing to Our Brains. The Atlantic Online. https://sdsuwriting.pbworks.com/w/file/fetch/83284144/03 Carr google.pdf

[2] Hooper, V. and Herath, C. (2014) Is Google Making Us Stupid? The Impact of the Internet on Reading Behavior. 2014 Proceedings 27th BLED E-Conference. http://aisel.aisnet.org/bled2014/1

[3] Swail, W.S. (2002) Higher Education and the New Demographics: Questions for Policy. Change Magazine, 34, 15-23.

[4] Torrisi-Steele, G. (2011) This Thing Called Blended Learning-A Definition and Planning Approach. In: Krause, K., Buckridge, M., Grimmer, C. and Purbrick-Illek, S., Eds., Research and Development in Higher Education: Reshaping Higher Education, Gold Coast, Australia, 360-371.

[5] Archee, R. (2008) Beyond E-learning Management Systems: Screencasting for Presentation and Practice, 6th CollECTeR Iberoamerica Conference, Madrid, 25-27 June 2008. 
http://www.imaginar.org/taller/ecollecter/fullpapers/p39-Beyond\%20E-learning.pdf

[6] Christensen, C.M., Horn, M.B. and Johnson, C.W. (2008) Disrupting Class: How Disrupting Innovation Will Change the Way the World Learns. McGraw-Hill, New York.

[7] Deering, D. and Creso, M. (2014) Financial Management of Canadian Universities: Adaptive Strategies and Fiscal Constraints. Tertiary Education and Management, 20, 207-24. http://dx.doi.org/10.1080/13583883.2014.919604

[8] Lamb, J. (2001) Blended Learning Is the New Buzz Phrase. Originally from FT.com. http://specials.ft.com/ftit/june2001/FT3M0640JNC.html

[9] Bersin, J. (2004) The Blended Learning Book. Pfeiffer, San Francisco.

[10] Means, B., Toyama, Y., Murphy, R.F. and Baki, M. (2013) The Effectiveness of Online and Blended Learning: A Meta-Analysis of the Empirical Literature. Teachers College Record, 115, 1-47. http://www.sri.com/sites/default/files/publications/effectiveness_of_online_and_blended_learning.pdf

[11] Bernard, R.M., Borokhovski, E., Schmid, R.F., Tamim, R.M. and Abrami, P.C. (2014) A Meta-Analysis of Blended Learning: From the General to the Applied. Journal of Computing in Higher Education, 26, 87-122. http://dx.doi.org/10.1007/s12528-013-9077-3

[12] Driscoll, M. and Carliner, S. (2005) Advanced Web-Based Training Strategies. Blended Learning as a Curriculum Design Strategy. ASTD Press, New York.

[13] Smith-Jaggars, S. (2014) Democratization of Education: For Whom? Online Learning and Educational Equity. Diversity \& Democracy, 17. http://www.aacu.org/diversitydemocracy/2014/winter/jaggars

[14] Xiu, D. and Smith Jaggars, S. (2013) The Impact of Online Learning on Students' Course Outcomes: Evidence from a Large Community and Technical College System. Economics Education Review, 37, 46-57. http://dx.doi.org/10.1016/j.econedurev.2013.08.001

[15] Kaznowska, E., Rogers, J. and Usher, A. (2011) The State of E-Learning in Canadian Universities, 2011: If Students Are Digital Natives, Why Don't They Like E-Learning? Higher Education Strategy Associates, Toronto. 